\title{
Condition Assessment of Heritage Timber Buildings in Operational Environments
}

\author{
Mengning Lyu ${ }^{1,2,3}$, Xinqun Zhu*3 and Qingshan Yang ${ }^{2,4}$ \\ ${ }^{1}$ School of Civil Engineering, Beijing Jiaotong University, Beijing, China. \\ ${ }^{2}$ Beijing's Key Laboratory of Structural Wind Engineering and Urban Wind Environment, \\ Beijing, China. \\ ${ }^{3}$ School of Computing, Engineering and Mathematics, Western Sydney University, Penrith, \\ Sydney, NSW 2751, Australia. *Corresponding author: xinqun.zhu@westernsydney.edu.au \\ ${ }^{4}$ School of Civil Engineering, Chongqing University, Chongqing, China.
}

\begin{abstract}
Due to the changing environments and aging, the structural resistance of the heritage buildings has been reduced significantly. It has become crucial to monitor and protect the architectural heritage buildings. The objective of this research is to monitor and assess the performance of the heritage Tibetan timber building in operational environments. A threestorey corridor part of the typical heritage building was chosen in the study. A long-term monitoring system was installed in the building to collect the structural response and the temperature. The detail finite element model was built based on the site investigation and existing documents, and updated based the temperature-based response sensitivity using the field monitoring data. The updated model was further evaluated using the static and dynamic analysis for condition assessment of the building in operational environments. The results show that the updated model is effective and accurate to predict the structural behaviour of the building in operational environments. Based on the temperature-based response sensitivity, it is capable of tracking structure performance throughout the life-cycle allowing for condition based maintenance and structural protection.
\end{abstract}

Keywords: historic buildings, condition assessment, temperature, response sensitivity 


\section{Introduction}

Due to the changing environment and aging, condition assessment of buildings is becoming increasingly important for their safety, especially for the heritage buildings. Structural health monitoring (SHM) is an effective tool to achieve the balance between structural safety needs and the respect for their architectural and culture value (De Stefano et al., 2016). SHM systems have been installed on heritage masonry buildings in Italy (Lorenzoni et al., 2013). The structural performance was evaluated using the collected data in the field. Once the damage has been identified, it is possible to take the appropriate measures to strengthen/retrofit the structure and avoid the collapse of the building. Recently, the Tibetan heritage buildings have attracted attention due to its historical and cultural value, and they have experienced large environmental changes in last few centuries. These heritage architectures are typical timber-framed buildings. Due to the specific working condition of these heritage buildings, there are substantial differences in the procedures for structural assessments of heritage timber buildings in operational environments. In this study, the emphasis is made on operational load evaluation and structural parameter identification for structures in operational environments.

A brief review on the operational load identification techniques developed in the last two decades is presented below. Methods based on response measurements have been proposed to estimate the external excitations on a structure (Law et al. 1997, Zhu and Law 2001). They are mostly based on the state space method, which relates the response, the system parameters and the input force with the Markov parameters. Kalman Filtering has been popularly used for highly accurate estimation on the state of a stochastic system. It has been popular in many industrial applications and academic researches (Kalman 1960, Chan et al. 1979, Pan and Law 2016) which is considered to be used for input estimation technique using the generalized least-squares approach.

Considering the specifics of heritage timber buildings operational conditions, thermal effect may be more significant as the temperature load generated by large ambient temperature variation is larger than those produced by the live load (Lyu and Yang 2016). The static and dynamic responses of the structure will be affected by thermal loads and it also affects the accuracy of the inverse analysis on the estimation of structural excitations and conditions (Sohn 2007). Several methods have been developed to remove the effect of temperature variations on the responses (Sohn et al. 2002, Deraemaeker et al. 2008, Balmès 
et al. 2009). However, these approaches assumed that the components due to thermal effects are orthogonal and uncoupled with other components of the responses. This requirement is seldom satisfied in practice. Presented herein is a new computational strategy to eliminate the thermal effect in measured responses. This approach directly models the thermal effects on the dynamic responses without the temperature information, which adopts force identification technique which has been researched extensively in the last two decades.

In addition to accurate operational loads, structural parameters for the building need to be clearly understood for condition assessment procedure. Heritage timber architecture is an important kind of buildings with unique 'Que-Ti' (corbel brackets) and tenon joints utilised as component connections (Chinese ancient architecture 1985). King et al. (1996) studied both the static linear and nonlinear characteristic of connections in a typical Chinese timber building by the experimental testing and numerical modelling. They proposed that the semirigid connection's stiffnesses were decreased with the deterioration on component's surface seriously during thousands of years of the construction. There are the limited research results on stiffness, especially for the heritage timber beam-column connections. It is noted that no accurate values can be adopted here to describe the stiffness of the joints (Maekawa et al. 1998, Seo et al. 1999, Uchida et al. 1998). There is also growing recognition that the uncertainties associated with assumed boundary and continuity conditions, material properties, mass and mass distribution, dead load distribution, etc., drastically reduces the accuracy of finite element models for heritage buildings.

Recently, a few researchers have tried to identify structural parameters of bridges using the temperature-based approach. Kulprapha and Warnitchai (2012) investigated the feasibility to monitor the structural health of multi-span pre-stressed concrete bridges using the ambient thermal loads and responses, such as strains, deflections and support reaction forces etc. Yarnold and Moon (2015) created the structural health monitoring baseline by utilizing the relationship between temperature changes and the strain/displacement responses. The thermal load is a slow-varying load compared with other dynamic loads. Lyu and Yang (2017) developed a recursive least-squares method to extract the thermal load of a bridge structure from measured acceleration responses. Lyu et al. (2017) identified beam-column connection stiffness from the field monitoring data based on temperature-based sensitivity analysis. In this paper, a finite element model of a typical heritage Tibetan building is built from the site investigation and the existing documents. The model is updated based on a temperature-based response sensitivity method using field temperature and strain response measurements. The updated model is further evaluated using the static and dynamic analysis of the building. The 
results show that the updated model is effective and accurate to predict the structural behaviour of the building in operational environments. Combining with the temperaturebased response sensitivity method, the structural parameters can be identified. The proposed approach is capable of tracking structure performance throughout the life-cycle allowing for condition based maintenance and structural protection.

\section{Typical Structures of Heritage Tibetan Timber Buildings}

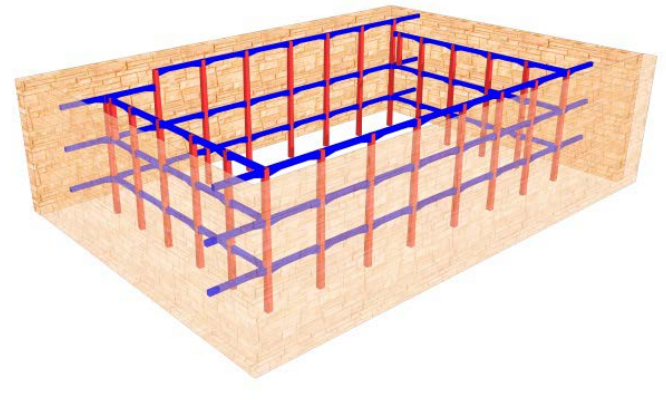

(a) The traditional timber building

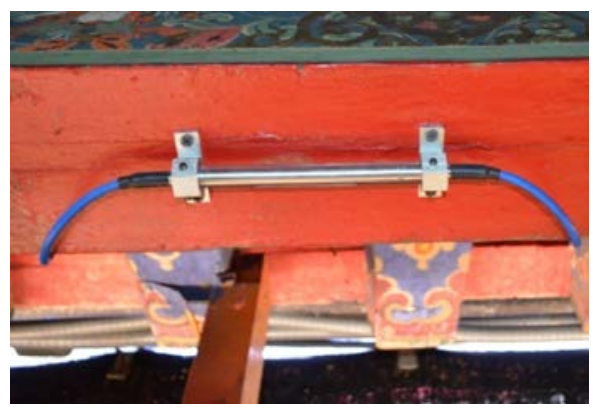

(c) The Fiber Bragg grating strain gauge

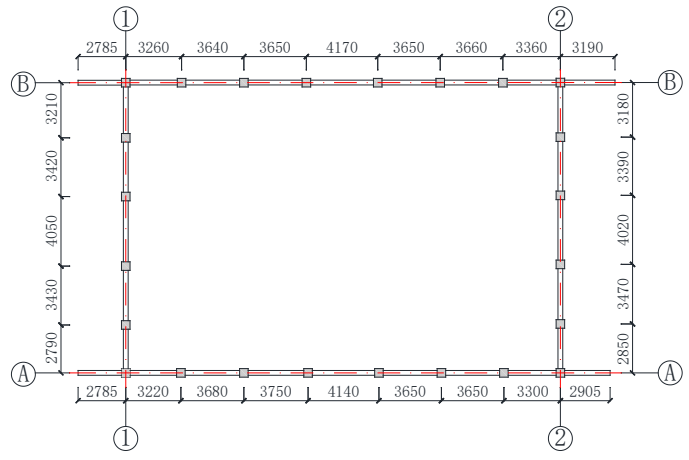

(b) Floor plan for wooden frame (unit: $\mathrm{mm})$

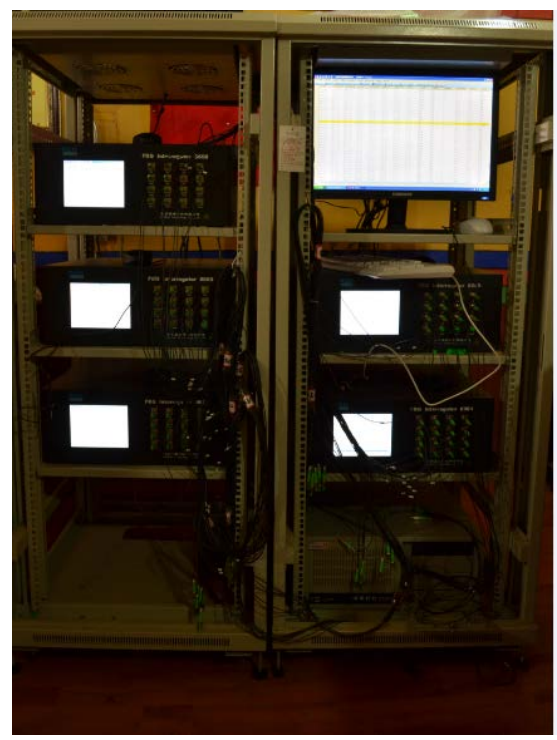

(d) The data acquisition system

Figure 1 A typical three-story corridor part of heritage Tibetan timber buildings

This study is to develop a strategy to monitor and assess the performance of the heritage Tibetan timber buildings. A typical three-storey corridor part of heritage Tibetan timber buildings has been used in this study, as shown in Figure 1(a). Figure 1(b) shows the detail floor plan of the wooden frame with $31.365 \mathrm{~m}$ long and $16.900 \mathrm{~m}$ wide. A long-term 
monitoring system has been installed in the building to collect the operational environmental data and structural responses. The Fiber Bragg grating strain gauge (FBG), as shown in Figure 1(c), is installed on the frame. The data acquisition system is based on the BGK-FBG8600 optical interrogator and each module has 16 channels, as shown in Figure 1(d). The frame is monitored continuously and the data is collected per hour. There are total 36 measurement points including 18 points on the beams and another 18 points on the columns. The strain and temperature at each point will be monitored simultaneously. The detail sensor arrangement on the frame is shown in Figure 2. Over three years monitoring data are available from the traditional building monitoring system, which provides a most unique opportunity for development of a reliable evaluation approach.

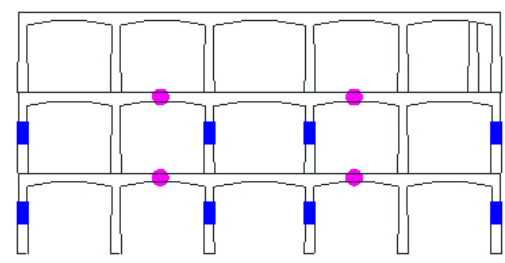

(a) East view

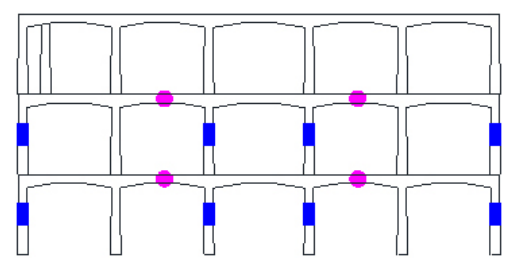

(c) West view

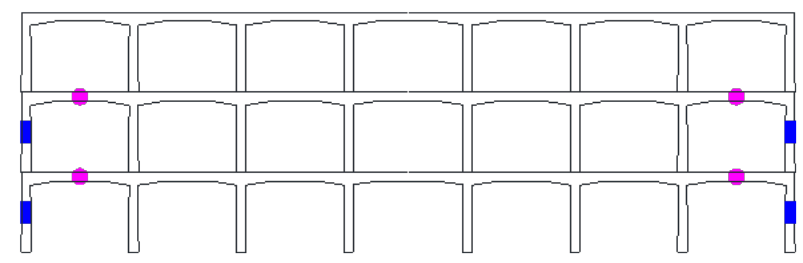

(b) South view

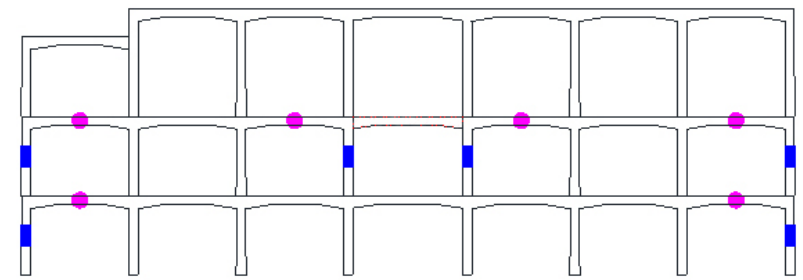

(d) North view

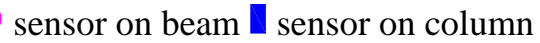

Figure 2 The frame model and sensor arrangement

The structural health monitoring procedure for heritage timber buildings mainly includes five steps: 1) carrying out a site investigation for collecting the detail information of the structure; 2) creating a finite element model based on the collected data; 3) designing a longterm monitoring system to be installed in the structure; 4) the finite element model updating and validation using the monitoring data; and 5) structural condition assessment and evaluation using the updating model. In the procedure, the reference finite element (FE) model is the basis for the structural performance monitoring under operational environments and structural condition assessment. To assess the structural condition of the building, it is essential to construct a model that accurately represents the structure. The complete description of the three-storey corridor FE model is provided below. 


\section{Numerical Modelling for Heritage Timber Buildings}

\subsection{Geometry}

Based on the site investigation, a 3D CAD model is a scratch representation of the building. The geometry information was from the organization of the heritage building and the purpose of the CAD model was to obtain an accurate representation of the building geometry. All structural beam and column members were drawn as lines and all wall components were drawn as 3D blocks. The 3D CAD model was later imported into the commercial software, ANSYS. Figure 3 illustrates the imported geometry in ANSYS.

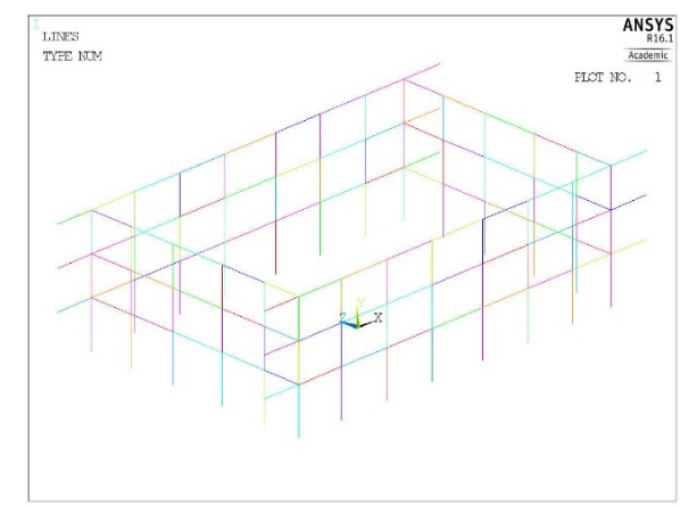

Figure 3 3D centerline geometry of the heritage timber frame

\subsection{Elements, Section Properties and Links}

As mentioned in Section 3.1, the global geometry of the structure included the members. Therefore, cross-sections of each member were created in ANSYS based on the collected information. The cross-section of beam members is $0.25 \mathrm{~m} \times 0.5 \mathrm{~m}$ and the cross section of column is varied from $0.25 \mathrm{~m} \times 0.25 \mathrm{~m}$ to $0.4 \mathrm{~m} \times 0.4 \mathrm{~m}$. The elements, section properties and links are custom defined for each FE model. The elements adopted in the model were selected to best reflect the behaviour of the structure. BEAM188 with six degrees of freedom per node was selected here to model the beam and column members. In the derivation of the load-deformation relationship for the timber components, the assumptions are as follow:

(a) The constituent materials behave elastically in both tension and compression.

(b) The bending rigidity of the timber element is assumed as constant along the length.

(c) Euler-Bernoulli beam is adopted for the beam element system in this study.

At locations where the compatibility was to be enforced between specific nodes, link elements were defined. Links do not have any section or material properties, but exist in a 
variety of forms such as rigid and pin, depending on how the user intends to relate the displacement and translation of one node to another. In this study, semi-rigid link elements were considered to attach the beam and column due to the character of heritage joints. COMBIN14 is a spring element used for the connection element between the column and beam.

\subsection{Material Properties}

The frame is surrounded by the 'Agatu' soil enclosure walls and the thickness of the wall is about $700 \mathrm{~mm}$. So the wall is very rigid and it is considered as boundary conditions in Section 3.5. Material properties were assigned to the structural timber for the FE model. The assigned properties are shown in Table 1.

Table 1 The Material Properties of the FE Model

\begin{tabular}{cc}
\hline Parameter & Timber \\
\hline Modulus of Elasticity(MPa) & 6435 \\
Poisson's Ratio & 0.1 \\
Density $\left(\mathrm{kg} / \mathrm{m}^{3}\right)$ & 418 \\
Thermal Expansion $\left(/{ }^{\circ} \mathrm{C}\right)$ & $0.8 \times 10^{-6}$ \\
Friction & 0.5 \\
\hline
\end{tabular}

\subsection{Joints}

One of the unique characteristics in typical Tibetan historic timber structures is the use of 'Que-Ti' as connections to transfer the loading between the beam and column with an increase of the bearing area at the end of the beam, and a decrease of the beam span leading to an improved shear and bending resistance at the beam end. It seldom involves nail or pin in its construction (Fang et al. 2001).

The beam-column joint of historic timber architectures, as shown in Figure 4, is typically a planar structural component supporting column from the top and beams coming in from two horizontal directions with the beam discontinuous at the top of the column. The thickened parts of the connecting members close to the intersection form the 'Que-Ti'. With consideration of this arrangement, three linear springs are used to simulate the behaviour of a 'Que-Ti' in which two of them are rotational springs with stiffnesses K1 and K2 to simulate the behaviour of the rotating restraint on the beam, and the other one with stiffness $\mathrm{K} 3$ has vertical compressive stiffness to simulate the compression behaviour perpendicular to grain as shown in Figure 5. The three spring stiffness matrices are assumed linear and uncoupled 
(Lyu et al. 2017).
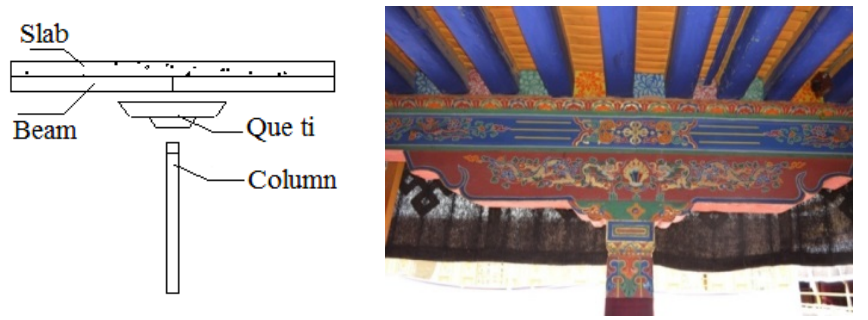

Figure 4. Composition of beam-column joints

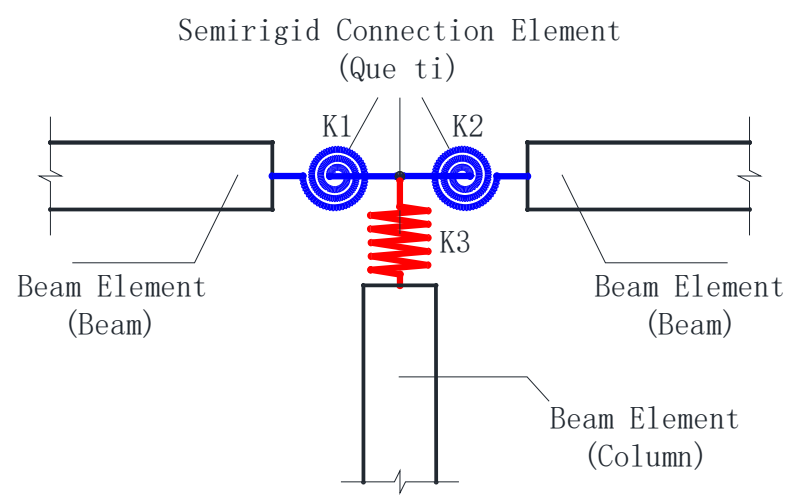

Figure 5. Simplified model of beam-column connection

\subsection{Boundary Conditions}

Boundary conditions in an FE model dictate how the model is globally supported and restrained from movements. This structure is surrounded by soil enclosure walls. The boundary conditions of the heritage building model consisted of nodal restraints at the ends of the side beam, which is shown in Figure 6. However, these walls actually carry the vertical and rotational loads. The information about its restraint for the longitudinal load is less as there are always gaps between the timber frames and walls. Considering the unknown longitudinal boundary condition, which can be treated as a semi-rigid connection and that only contains the longitudinal compressive stiffness. In this case, the end part of the beam inserted into walls can be studied as a pile and the boundary condition can be simplified as the friction between the soil and the pile, whose stiffness can be assumed as Winkler springs. 


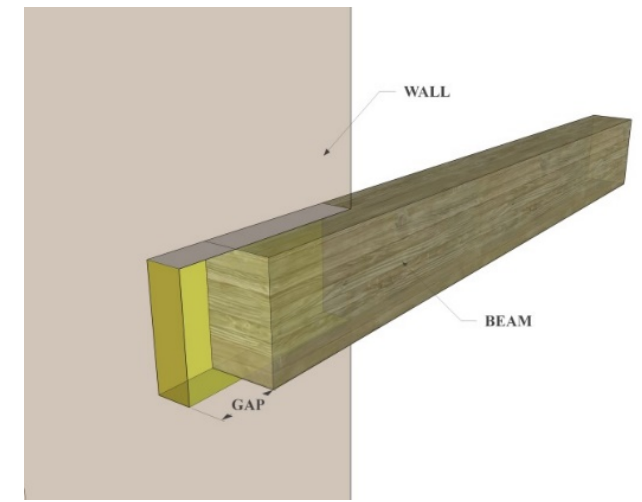

Figure 6 The boundary conditions of the heritage building

\subsection{Loading}

Two types of loading were of importance in this study. This includes thermal and dead loads. Thermal loads were applied through nodal temperature inputs. The quality of the floor slab and the roof is treated as the mass element added into the frame structure, whose gravity density is $20 \mathrm{kN} / \mathrm{m}^{3}$, and the thickness of the floor and roof are $200 \mathrm{~mm}$ and $300 \mathrm{~mm}$ respectively. Based on the long-term monitoring data (Dai et al., 2016), less than $3 \%$ of the total strain is caused by other dynamic loads such as crowded loading and wind loading. The low-pass filter has also been used to remove the high-frequency components due to other dynamic loads. The temperature load is the only excitation considered in this study.

\section{Finite Element Model Updating}

For a general finite element model of a linear elastic time-invariant system with m elements, the strain caused by the thermal variation $[\varepsilon]$ is given by

$$
[\varepsilon]=[\mathbf{B}][\mathbf{K}]^{-1}[\mathbf{F}]
$$

Since the relationship between the thermal strain and the temperature variation is treated as a linear function in this study, Eq. (1) can be further rewritten as

$$
\left[\begin{array}{c}
\varepsilon_{i}^{1} \\
\varepsilon_{i}^{2} \\
\vdots \\
\varepsilon_{i}^{m-1} \\
\varepsilon_{i}^{m}
\end{array}\right]=[\mathbf{B}][\mathbf{K}]^{-1} \alpha \mathrm{EA}\left[\begin{array}{c}
\Delta T_{i}^{1} \\
\Delta T_{i}^{2} \\
\vdots \\
\Delta T_{i}^{m-1} \\
\Delta T_{i}^{m}
\end{array}\right] \quad(i=1,2, \ldots, n)
$$

where $[\mathbf{B}]$ and $[\mathbf{K}]$ are the system strain-displacement relation matrix and stiffness matrix respectively. $\Delta T_{i}^{j}$ is the temperature variation of the jth element at the ith time step and $\alpha$ is 
the thermal expansion coefficient vector. $\mathrm{E}$ is the modulus of elasticity and $\mathrm{A}$ is the crosssectional area of the member. $m$ is the total number of elements in the structure and $n$ is the total number of time steps.

The difference of responses from measurements and calculation is obtained

$$
[\Delta \mathbf{R}]=[\boldsymbol{\varepsilon}]_{\mathrm{c}}-[\boldsymbol{\varepsilon}]_{\mathrm{m}}=[\mathbf{B}][\mathbf{K}]^{-1} \alpha E A\left[\begin{array}{c}
\Delta T_{i}^{1} \\
\Delta T_{i}^{2} \\
\vdots \\
\Delta T_{i}^{m-1} \\
\Delta \mathrm{T}_{i}^{m}
\end{array}\right]-\left[\begin{array}{c}
\varepsilon_{i}^{1} \\
\varepsilon_{i}^{2} \\
\vdots \\
\varepsilon_{i}^{m-1} \\
\varepsilon_{i}^{m}
\end{array}\right]_{m} \quad(i=1,2, \ldots, n)
$$

Differentiating both sides of Equation (2) with respect to the stiffness parameter of the system, the strain sensitivity matrix can be written as

$$
S_{i}=\frac{[\partial \varepsilon]}{\left[\partial p_{i}\right]}=[\mathbf{B}][\mathbf{K}]^{-1} \frac{\partial[\mathbf{K}]}{\partial p_{i}}[\mathbf{K}]^{-1} \alpha E A\left[\begin{array}{c}
\Delta T_{i}^{1} \\
\Delta T_{i}^{2} \\
\vdots \\
\Delta T_{i}^{m-1} \\
\Delta T_{i}^{m}
\end{array}\right]
$$

where $\left\{p_{i}, i=1,2, \mathrm{~L} m\right\}$ are unknown stiffness parameters.

The length of the sensitivity vector is the same as the number of measured data points, and the sensitivity vector corresponding to a fractional change of stiffness in the ith element can be rewritten as $S_{i}$. The sensitivity vectors for all structural elements can be computed, and the sensitivity matrix is assembled as

$$
\mathrm{S}=\left[\begin{array}{llll}
\mathrm{S}_{1} & \mathrm{~S}_{2} & \cdots & \mathrm{S}_{m}
\end{array}\right]
$$

The identification equation for the stiffness parameters of a structure can be expressed as

$$
\mathrm{S} \Delta \mathrm{P}=\Delta \mathrm{R}
$$

where $\Delta P$ is the unknown incremental stiffness parameters. Eq. (6) can be solved with an iterative Gauss-Newton method and Tikhonov regularization is used for optimizing the following objective function in the kth iteration as

$$
\begin{gathered}
P_{k}=P_{k-1}+\left[\mathbf{S}_{k}^{T} \mathbf{S}_{k}\right]^{-1} \mathbf{S}_{k}^{T} \Delta \mathbf{R} \\
J\left(\Delta P_{k}, \lambda_{k}\right)=\left\|\mathbf{S}_{k-1} \Delta P_{k}-\Delta \mathbf{R}\right\|+\lambda_{k}\left\|\Delta P_{k}\right\|^{2}
\end{gathered}
$$

where $\lambda_{k}$ is the regularization parameter in the kth iteration obtained with the L-curve method (Hansen, 1992), $\mathrm{S}_{\mathrm{k}-1}$ is the sensitivity matrix with which the structural model is updated.

The structural stiffness matrix is updated after $\Delta P_{k}$ is obtained. Then the structural 
responses and the sensitivity matrix can be re-calculated based on the updated stiffness matrix, and the vector $\Delta P_{k}$ for the next iteration is calculated until the convergence is achieved with the following criterion as

$$
\frac{\left\|P_{k+1}-P_{k}\right\|}{P_{k}}<\text { Tol }
$$

The value of $\mathrm{Tol}$ is such selected to suit the difficulty with convergence of the identified results there is noise effect.

In this study, the method was utilised for model updating. The connection stiffnesses and the loads on the structure were identified based on the a-priori FE model (Lyu and Yang 2016). The accuracy of the updated model needs to be checked to make sure the mechanical behaviours were modelled as anticipated. Therefore, the long-term monitoring data was divided into two groups: the first group was used for model updating and the second group was for model validation. Over three years monitoring data are available from the heritage building monitoring system, which provides a most unique opportunity for development of a reliable evaluation approach. The measuring duration lasts for 24 hours per day and the data is collected per hour. The selected data is collected periodically every single day at a specific time. The first 600-days data was defined as the first group utilised for model update and the rest 500-days data was considered as the second group for model validation. Taking the data from one sensor for example, the strain history curve and temperature history curve are shown in Figure 7. The temperature was assumed to be the same in a floor.

The measured temperature was treated as a force function and the simulated results were compared with the second group data. Based on the temperature-drive method, the identified rotational stiffness is from $3105 \mathrm{kNm} / \mathrm{r}$ to $8699 \mathrm{kNm} / \mathrm{r}$ and its average value is $6217 \mathrm{kNm} / \mathrm{r}$, the identified vertical compressive stiffness is from $69835 \mathrm{kN} / \mathrm{m}$ to $10246 \mathrm{kN} / \mathrm{m}$ and its average value is $90173 \mathrm{kN} / \mathrm{m}$, and the identified longitudinal compressive stiffness is from $26884 \mathrm{kN} / \mathrm{m}$ to $36903 \mathrm{kN} / \mathrm{m}$ and its average value is $29989 \mathrm{kN} / \mathrm{m}$. The identified results show that the 'Que-Ti' connections are similar but some stiffness values at both sides are quite different. The main reason is that the beam in the 'Que-Ti' is not a continuous beam. Both sides of the connection are independent. The damage may be happened in one beam but the another one is good (Lyu et al., 2017). Four measurement components were selected for comparison and the location were on side span column of the top floor, on side span column of the ground floor, on middle span beam (bottom) of the top floor and on the middle span beam (bottom) of the second floor respectively, which are shown as in Figure 8. 


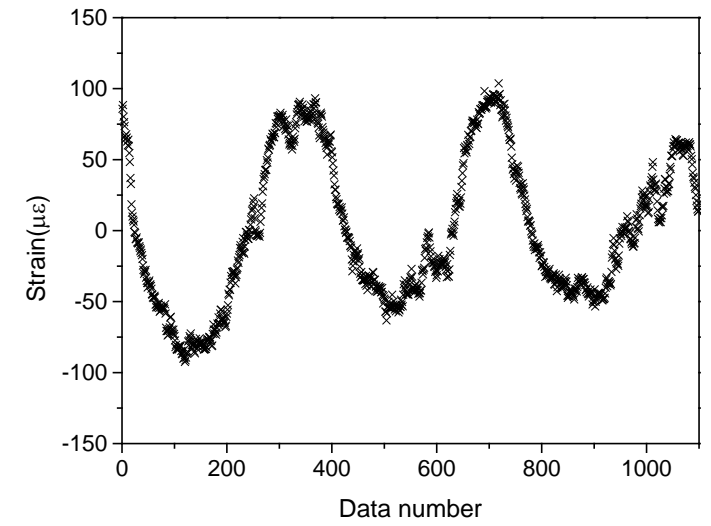

(a) Strain time history

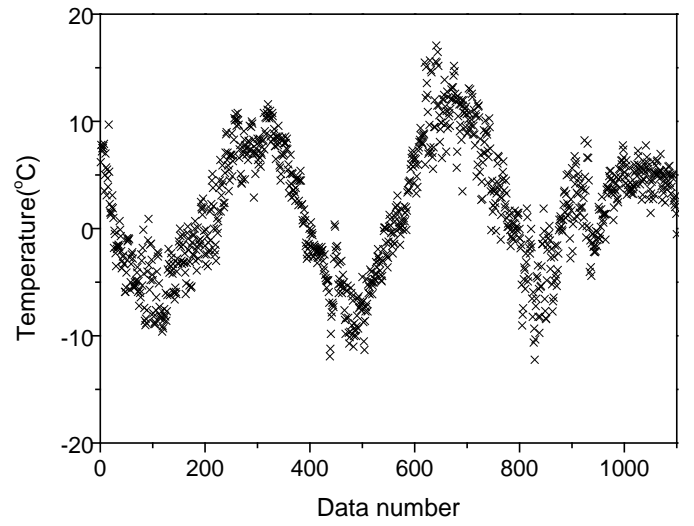

(b) Temperature changes

Figure 7 Data from Fiber Bragg grating strain gauges
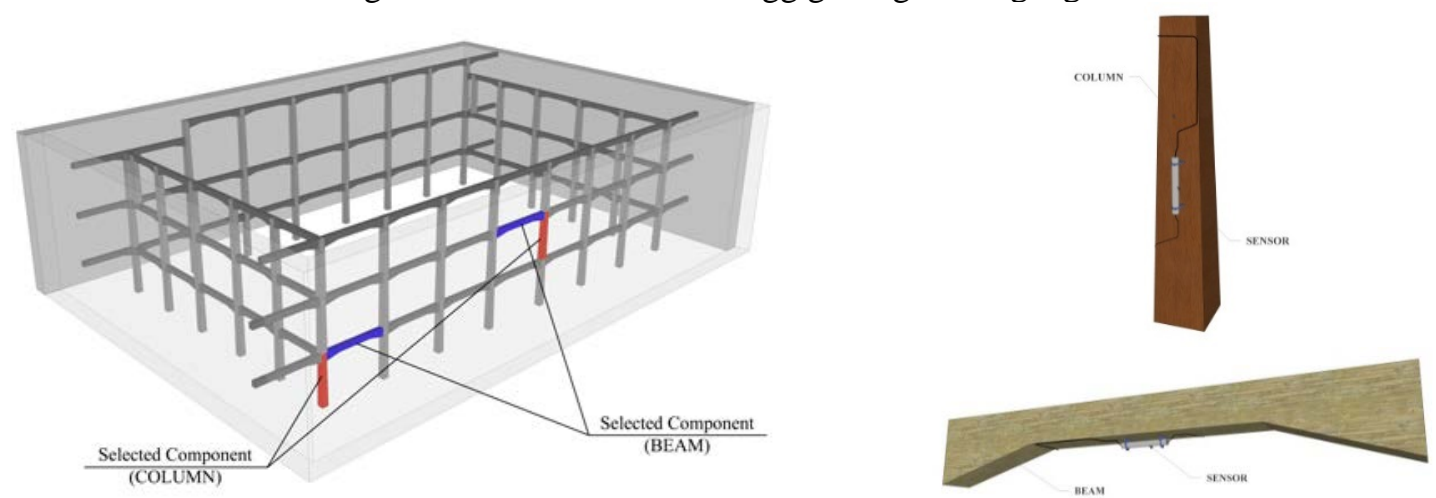

Figure 8 The selected components for comparison

Compared with the calculated results with a-priori model, the results of strains on the column can be seen in Figures 9(a) and 8(b), which reflect that the calculated strains based on the updated model are quite close to the measurement value. And the stain curves on the beam are shown in Figures 9(c) and 8(d). The results from the updated model agree well with field measurements. These figures illustrate the fact that the updated model could support a great simulation results although in non-sensitive components like columns.

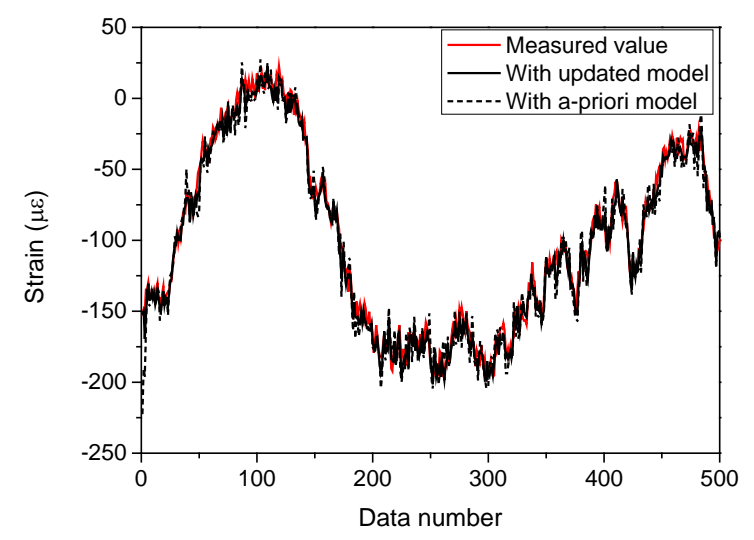

(a) Site on side span column of the top floor

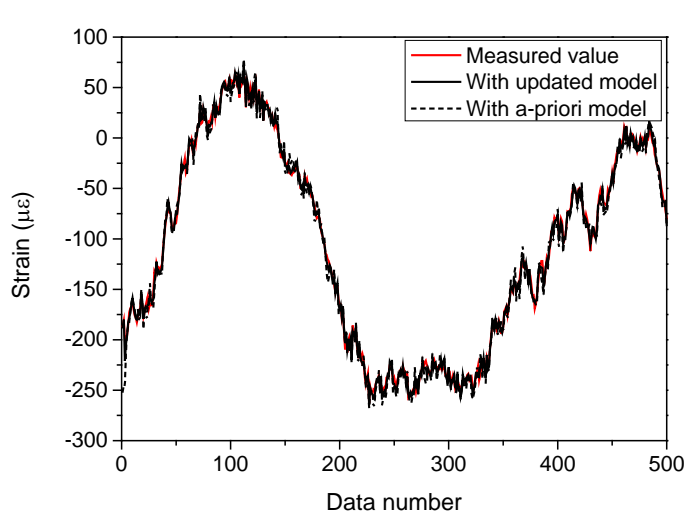

(b) Site on side span column of the ground floor 


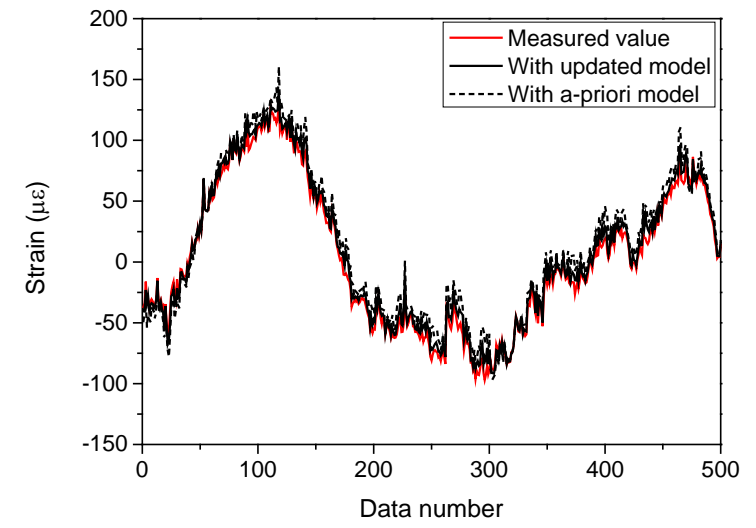

(c) Site on middle span beam of the top floor

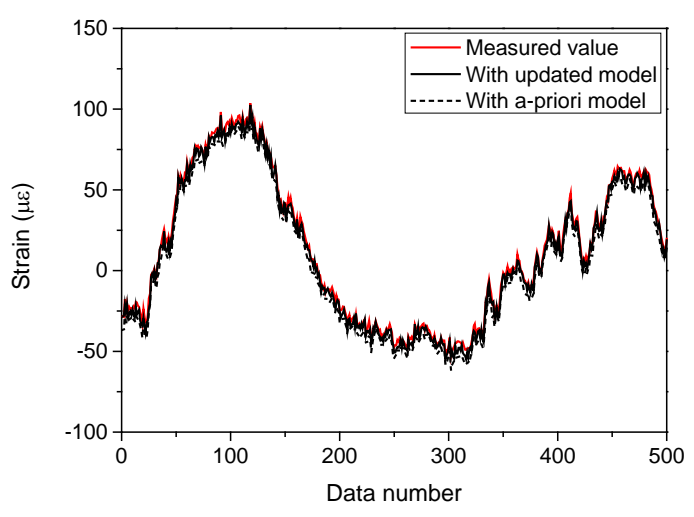

(d) Site on the middle span beam of the 2nd floor tory curves compared with measured data

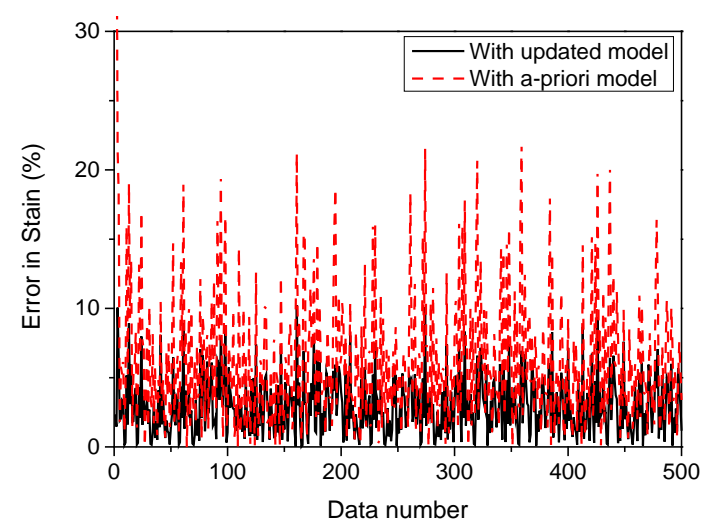

(a) Site at side span column on the top floor

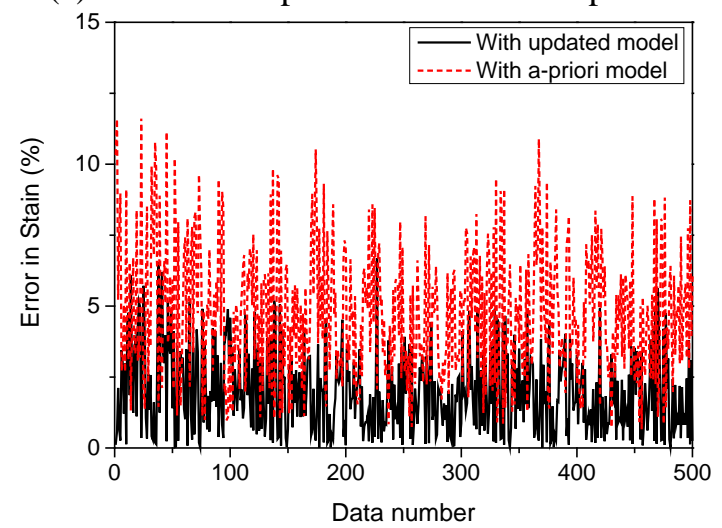

(c) Site at middle span beam on the top floor (b) Site at side span column on the ground floor

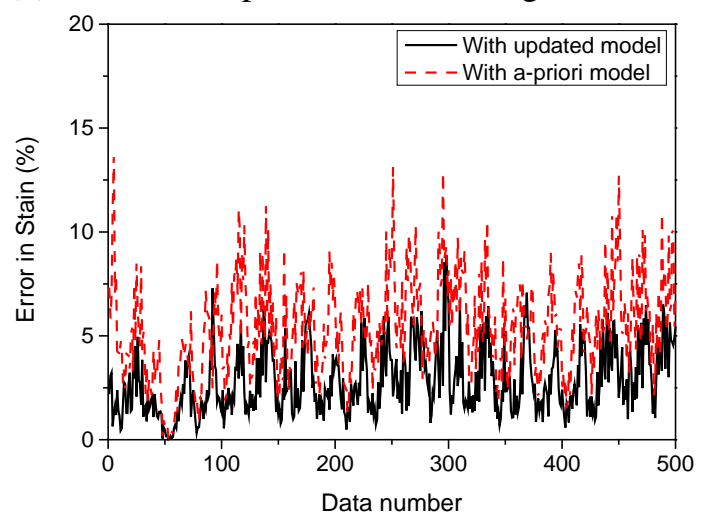

(d) Site at the middle span beam on the 2nd floor Figure 10 Errors in calculated results of strain history curves

The errors in calculation results are shown in Figure 10. The errors with updated model are all less than $10 \%$ on column elements and $7 \%$ on beam elements respectively, which are much smaller than that with a-priori model whose errors are around $16 \%$ on column elements and $10 \%$ on beam elements respectively. All results above reflect that the simulated results based on the updated model match the measured values greatly. The discrepancy was within $10 \%$ and therefore considered adequate. 


\section{Applications for Condition Assessment of Heritage Timber Buildings}

The stiffnesses of joints and boundary conditions have been obtained based on the temperature-based response sensitivity in Section 4 and those identified stiffness results have been applied into the reference FE model of the heritage building in ANSYS, as shown in Figure 11. Then the finite element model has been updated which can be used to evaluate the performance of the building. In this section, the static and dynamic analysis using the reference model has been conducted to show its applications, as listed in Table 2. Both static and dynamic analyses are adopted here to evaluate the efficiency of the updated model and compare the calculated values with design values.

Table 2 The applications of the updated model

\begin{tabular}{|c|c|c|}
\hline \multirow[t]{2}{*}{ Static analysis } & Dead Loads & $\begin{array}{c}\text { Symmetry } \\
\text { Order of Magnitude (stress \& displacement) } \\
\text { Reactions } \\
\text { Unintended Discontinuity } \\
\end{array}$ \\
\hline & Temperature Loads & $\begin{array}{l}\text { Deformed Shape } \\
\text { Unintended Discontinuity }\end{array}$ \\
\hline Dynamic analysis & - & $\begin{array}{c}\text { Mode Shapes } \\
\text { Order of Magnitude (frequency) } \\
\text { Unintended Discontinuity }\end{array}$ \\
\hline
\end{tabular}

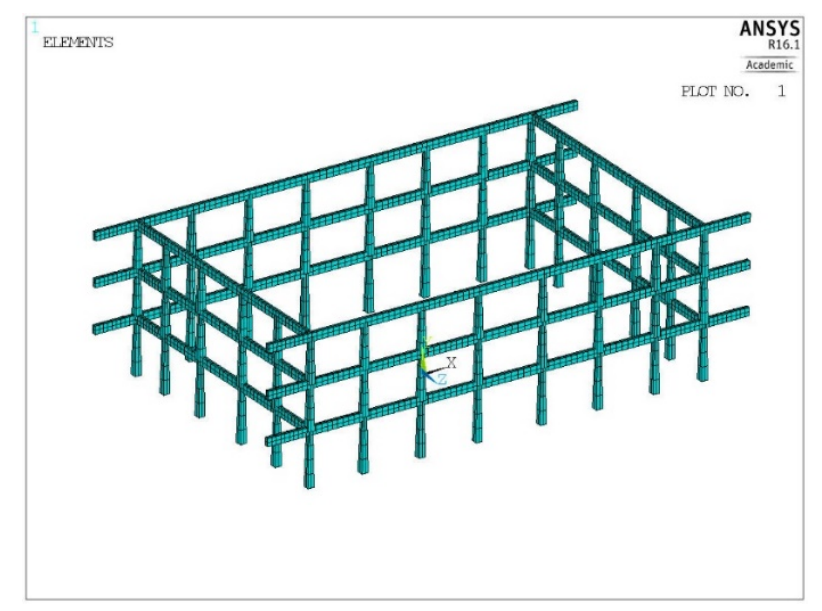

Figure 11 Heritage Timber frame FE Model

\subsection{Static Evaluation}

A linear static analysis was adopted here by considering the self-weight of the three-storey corridor building. The first item to be evaluated was symmetry of the reactions about the longitudinal axis of the structure. Considering the geometry is not symmetrical and the element section of each part is not the same, the symmetry about the structure cannot be used 
for error-screening.

The second item to be evaluated was the static stress and displacement responses. The structural members exhibited the peak stress of 2.6 MPa at the top of side column on the top floor. The design stress value of timber to construct the structure was $16 \mathrm{MPa}$. Based on the fact that there is a high dead load to live load ratio, it is acceptable that stresses due to the dead load contribute to $80 \%$ of the allowable stress. The maximum vertical displacement response from the building happened at the mid-span beam on the top floor. The magnitude was roughly $9 \mathrm{~mm}$.

The reactions were also evaluated to ensure the mass of the structure was reasonably accurate. The vertical reactions were totalled and compared to the mass of the structure from the original information. The discrepancy between the vertical reactions and the documented structure mass were within $7 \%$ and therefore considered adequate.

The final item was the evaluation of the deformed shape for any irregularities or discontinuities. Figure 12 illustrates the undeformed and deformed shapes of the corridor structure under self-weight. Based on this, all discontinuities can be rectified.

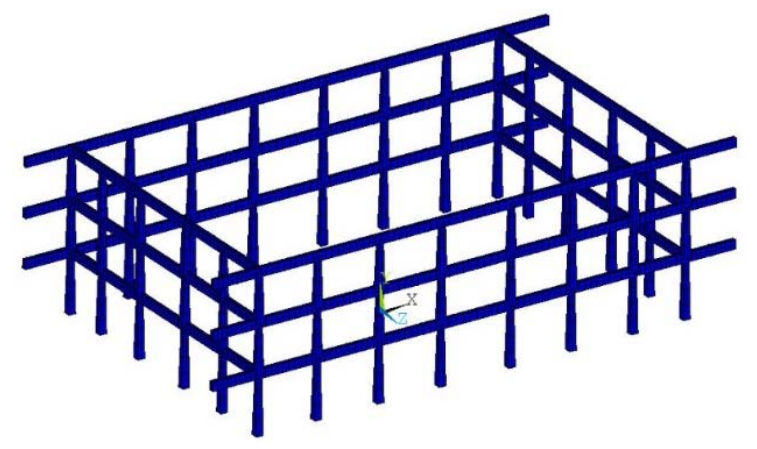

(a) Undeformed shape

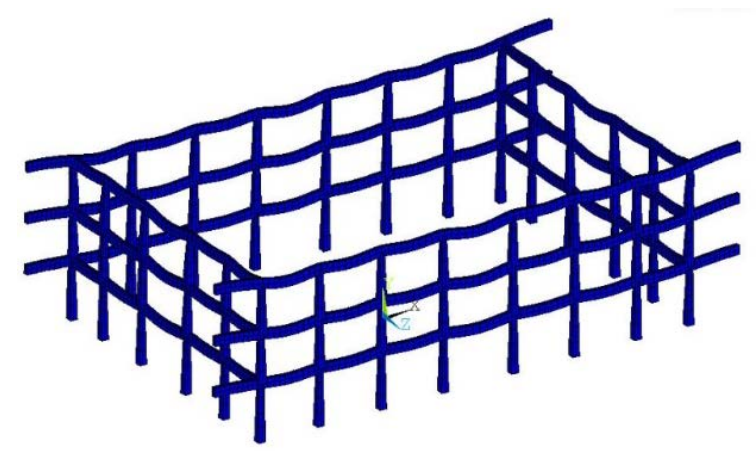

(b) Deformed shape

Figure 12 The deformation of the building due to the self-weight only

\subsection{Static Behaviour of the Building Subjected to Temperature Loading}

A linear static analysis was performed for a $10^{\circ} \mathrm{C}$ temperature increase in the corridor frame structure. The first error-screening item was to evaluate the deformed shape. The boundary conditions were checked to make sure the mechanical behaviours were modelled as anticipated. Figure 13 illustrates the undeformed and deformed shapes of the structure under the temperature increase. It can be observed that the frame expands as intended from the assigned boundary conditions. 


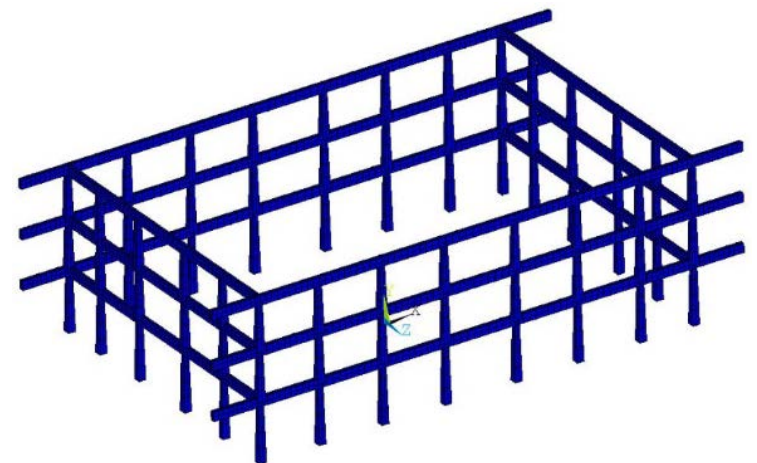

(a) Undeformed shape

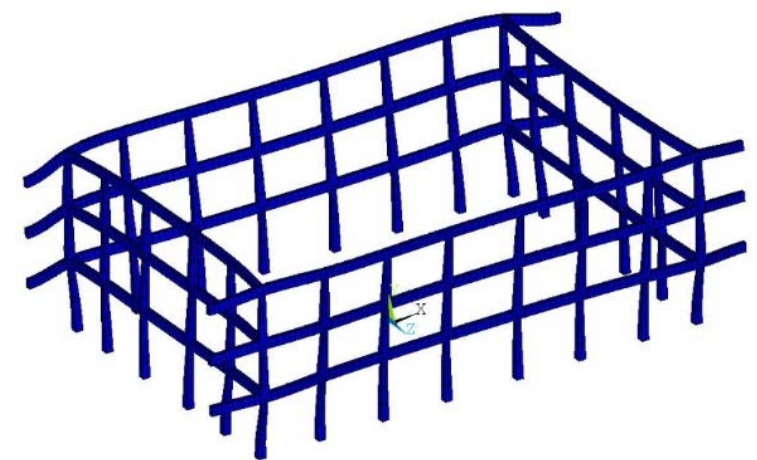

(b) Deformed shape

Figure $13 \mathrm{FE}$ model shape due to temperature increase only

The next temperature analysis for the error-screening measure was the evaluation of any irregularities or discontinuities. The deformed shape can also be used here to check for any additional irregularities or discontinuities issues with the model.

\subsection{Dynamic Evaluation}

The modal analysis was also performed on the arch span model. The first and second checks were the mode shapes and frequencies of the structure. A vibration study of the corridor structure was conducted (Lyu et al. 2017). The aim was to extract the first few fundamental modes from ambient vibration measurements. By the stochastic subspace approach, the first mode of the frame was along the $\mathrm{Z}$ axis direction with a frequency of $6.57 \mathrm{~Hz}$.

The a-priori FE model produced similar mode shapes to those obtained from ambient vibration testing. The a-priori frequency for the first mode was $6.91 \mathrm{~Hz}$ resulting in a $6 \%$ difference. Figure 14 illustrates the first mode shape of the frame ( $\mathrm{Z}$ axis direction). The mode shapes and percent differences were considered reasonable for comparison of a preliminary field study with an a-priori FE model.

Last, the model was evaluated for any irregularities or discontinuities. The mode shapes were utilized here again to check for any additional issues with the model.

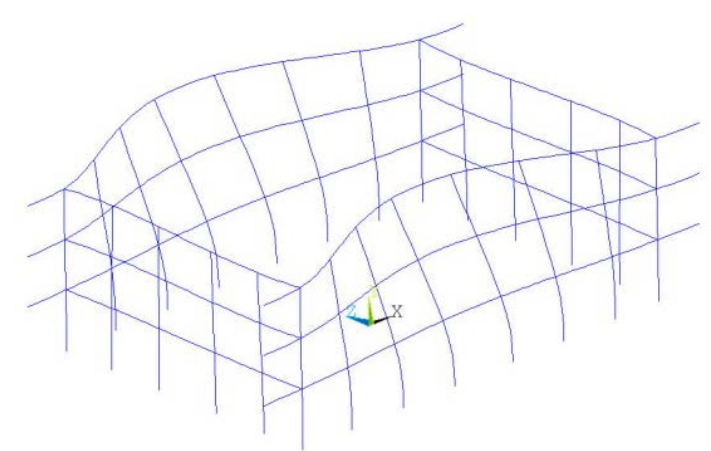

(a) Isometric View

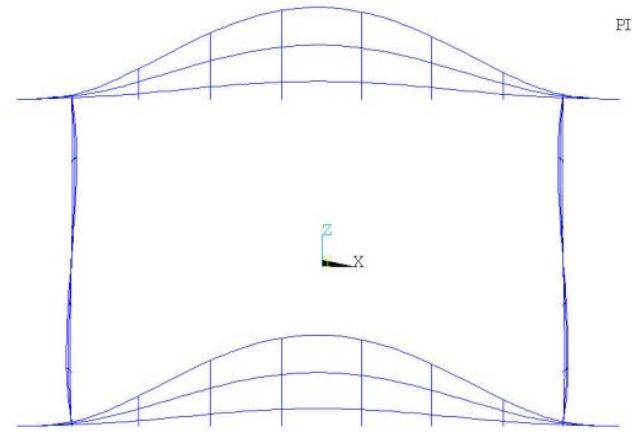

(b) Plan View 


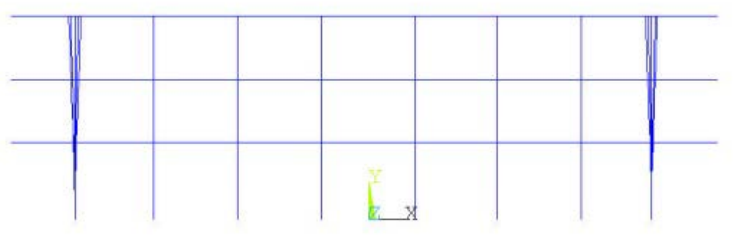

(c) Elevation View

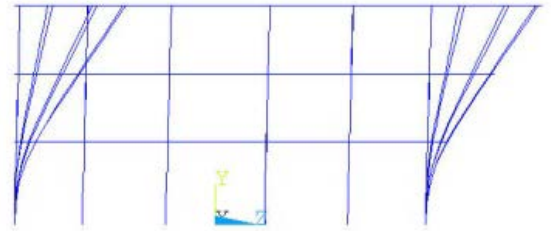

(d) End View

Figure 14 The First Mode Shape

\section{Conclusions}

An a-priori finite element model has been constructed from the site investigation and updated using the field monitoring data. The accuracy and effectiveness of the updated finite element model and the load effect were checked using field measured values. The model is useful to further understand the structural behaviour of the heritage timber building in operational environments. Combining with the temperature-based sensitivity analysis, the performance of the heritage Tibetan timber building can be characterized by field monitoring structural responses using the updated finite element model. The structure performance throughout the life-cycle allowing for proactive maintenance and preservation to be performed can be tracked based on the updated finite element model.

\section{Acknowledgments}

The work described in this paper was supported by Key Projects in the National Science \& Technology Pillar Program during the Twelfth Five-year Plan Period on Grant 2015BAK01B02 and National Natural Science Foundation of China on Grant 51338001 and 51422801. The financial support of the China Scholarship Council (CSC) was also acknowledged.

\section{References}

Balmès, É., Basseville, M., Mevel, L. and Nasser, H. Handling the temperature effect in vibration monitoring of civil structures: a combined subspace-based and nuisance rejection approach. Control Engineering Practice, 2009, 17(1) : 80-87.

Chan, Y. T., Hu, A. G. C. and Plant, J.B. A Kalman filer based tracking scheme with input estimation. IEEE Transactions on Aerospace and Electronic Systems, 1979, 15: 237-244.

Chinese ancient architecture [M]. Tsinghua University Press, Beijing, China, 1985. 
Deraemaeker, A., Reynders, E., DeRoeck G. and Kullaa, J. Vibration-based structural health monitoring using output-only measurements under changing environment. Mechanical Systems and Signal Processing, 2008, 22(1) :34-56.

De Stefano A., Matta E. and Clemente P. Structural health monitoring of historical heritage in Italy: some relevant experiences. Journal of Civil Structural Health Monitoring, 2016, 6(1): 83-106.

Fang, D. P., Iwasaki, S., Yu, M. H. and Shen, Q. P. Ancient Chinese timber architecture. II: dynamic characteristics. Journal of Structural Engineering, ASCE, 2001, 127(11): 1358-1364.

Kalman, R. E. A new approach to linear filtering and prediction problem. Journal of Basic Engineering, 1960, 82 (1):35-45.

King, W. S., Yen, J. Y., and Yen, Y. N. Joint characteristics of traditional Chinese wooden frames. Engineering structures, 1996, 18(8): 635-644.

Kulprapha, N. and Warnitchai, P. Structrual health monitoring of continuous prestressed concrete bridges using ambient thermal responses. Engineering Structures, 2012, 40: 20-38.

Law, S. S., Chan, T. H. T. and Zeng, Q. H. Moving force identification: A time domain method. Journal of Sound and Vibration, 1997, 201 (1):1-22.

Lorenzoni F., Casarin F., Modena C., Caldon M., Islami K. and Da Porto F. Structural health monitoring of the Roman Arena of Verona, Italy. Journal of Civil Structural Health Monitoring, 2013, 3(4): 227246.

Lyu, M.N. and Yang, Q.S. Estimation of thermal load in members of a structure from measured accelerations. International Journal of Structural Stability and Dynamics, 2016, 16(10).

Lyu, M.N., Zhu X.Q., and Yang Q.S. Connection stiffness identification of historic timber buildings using temperature-based sensitivity analysis. Engineering Structures, 2017, 131: 180-191.

Maekawa, H., and Kawai, N. Microtremor measurement on Japanese traditional wooden houses which are important cultural properties. Proceedings of the World Conference on Timber Engineering, Presses Polytechniques et Universitaires Romandes, Montreux, Switzerland, 1998. 40-47.

Pan, S. W. and Xiao, D., Xing, S. T., Law, S. S., Du, P. Y. and Li, Y. J. A general Extended Kalman Filter for simultaneous estimation of system and unknown inputs. Engineering Structures, 2016, 109: 8598.

Seo, J.M., Choi, I.K., and Lee, J.R. Static and cyclic behavior of wooden frames with tenon joints under lateral load. Journal of Structural Engineering ASCE, 1999, 125(3): 344-349.

Sohn, H. Effects of environmental and operational variability on structural health monitoring. Philosophical Transactions of the Royal Society A, 2007, 365(1851):539-560.

Sohn, H., Worden K. and Farrar, C. R. Statistical damage classification under changing environmental and operational conditions. Journal of Intelligent Material Systems and Structures, 2002, 13(9): 561574.

Uchida, A., et al. Dynamic characteristics in Japanese traditional timber buildings. Proceedings of the World Conference on Timber Engineering, Presses Polytechniques et Universitaires Romandes, Montreux, Switzerland, 1998. 34-41. 
Yarnold, M.T. and Moon, F.L. Temperature-based structural health monitoring baseline for long-span bridges. Engineering Structures, 2015, 86: 157-167.

Zhu X. Q. and Law, S. S. Identification of moving loads on an orthotropic plate. Journal of Vibration and Acoustics, 2001, 123 (2): 238-244. 